\title{
Purchase of Contraceptive Methods in Kongo Central Province, the Democratic Republic of Congo: Data from the Lelo Family Planning Mini-Campaign Survey
}

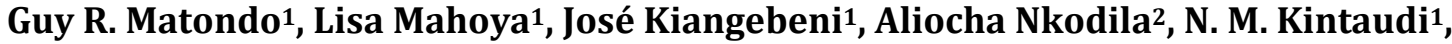 \\ Felix K. Minuku1', Kalonji A. Ntumba1, Ngwala P. Lukanu1,2* \\ ${ }^{1}$ Soins de Santé Primaires en Milieu Rural, Kinshasa, Congo \\ ${ }^{2}$ Family Medicine Department, School of Medicine, Protestant University of Congo, Kinshasa, Congo \\ Email: *phlukanu@yahoo.fr
}

How to cite this paper: Matondo, G.R., Mahoya, L., Kiangebeni, J., Nkodila, A., Kintaudi, N.M., Minuku, F.K., Ntumba, K.A. and Lukanu, N.P. (2021) Purchase of Contraceptive Methods in Kongo Central Province, the Democratic Republic of Congo: Data from the Lelo Family Planning MiniCampaign Survey. Open Journal of Obstetrics and Gynecology, 11, 553-562. https://doi.org/10.4236/ojog.2021.115051

Received: March 27, 2021

Accepted: May 16, 2021

Published: May 19, 2021

Copyright $\odot 2021$ by author(s) and Scientific Research Publishing Inc. This work is licensed under the Creative Commons Attribution International License (CC BY 4.0).

http://creativecommons.org/licenses/by/4.0/ (c) (i) Open Access

\begin{abstract}
Background and aim: Access to contraceptive methods remains low in the world in general and in Sub-Saharan Africa (SSA). Data of these contraceptive methods in rural areas of the Democratic Republic of Congo (DRC) remain poorly known. The aim is to identify the socio-demographic characteristics of clients associated with purchasing contraceptives methods via different distribution system in Kongo Central province. Methods: Cross-sectional study including data from mini Lelo Family Planning contraceptive method distribution campaigns organized in 11 health zones of Kongo Central province, from January to March 2020 by community-based distributors (DBC), learner DBCs (DBCa), graduated DBCs $(\mathrm{DBCg})$ and clinical providers $(\mathrm{CP})$. Results: The median age of clients was 25 years old. A quarter of them were men and almost half of the clients were in a conjugal relationship and $46.5 \%$ were single. The majority (70.4\%) had a high school education. The male condom was the most requested method during Lelo Family Planning, followed by implants. Natural methods remain the methods preferred by clients $<20$ years and single; modern methods by those aged $>25$ years. Among the hormonal methods, the implant was the most popular modern method, while the short and long-lasting injectable hormonal methods were more in demand by women $<25$ years of age. Conclusion: Natural methods are still the most preferred among male clients despite the poor protection they provide. Modern methods have to be promoted for male's partners to assure better couple protection especially in rural area where maternal mortality remains high.
\end{abstract}




\section{Keywords}

Profile, Clients, Prevalence, Contraceptive

\section{Introduction}

The use of contraceptive methods can prevent nearly 230 million births each year and family planning is the main strategy for preventing unintended pregnancies [1] [2]. The rapid reduction in fertility rates around the world from a total fertility rate (mean number of births per woman) from $4-7$ births in the early 1970 to $2-6$ births in the late 2000 is attributed mainly to the increase in the use of contraceptives methods [2].

Although organized family planning (FP) was introduced in the 1950 in developing countries to slow rapid population growth, it has emerged as a key public health strategy to improve maternal and child health [3]. Contraception and birth spacing have non-contraceptive benefits for women [4] [5]. The use of contraception has also improved child survival thanks to the spacing of births and the reduction of family constraints on often scarce resources [6] [7].

In high-income countries (HIC), more than $70 \%$ of women have access to a contraceptive method [8]. In Africa, where the burden of maternal mortality is highest, barely $24 \%$ of women of childbearing age have access to a modern contraceptive method [9]. This prevalence is still very low in SSA, where it is $2.5 \%$ in rural areas against 9\% in urban areas [9]. In the Democratic Republic of Congo (DRC), it is $5.4 \%$. The proportion of women at reproductive age who have an unmet need for FP is high. It was $24 \%$ in 2010-13 [10]. Modern contraception is not widely used in SSA because contraceptives are not available there and also, culturally, they are not accepted [11]. In order to improve this use, international agencies are supporting health structures with a range of contraceptives. In the DRC, the Family Health Association (ASF), Santé en milieu Rural (SANRU) and the United Nations Population Fund (UNFPA) are among the organizations that support these activities [12].

The Health Zones (HZs) of Kongo Central province have been among the HZs supported in family planning for more than 15 years [13] but in terms of the use of contraceptive methods, data has so far remained unknown. Moreover, even taking into account administrative contraceptive methods, contraceptives are not used by all women of childbearing age who need them. The reasons for this non-use are not so far known. The aim of this study is to identify the socio-demographic characteristics of clients associated with the purchase of one of the contraceptive methods in the province of Kongo Central.

\section{Methods}

This is a cross-sectional study of clients recruited during mini-campaigns called Lelo PF (Family Planning Day) organized from January to March 2020 in 11 
health zones in Kongo Central Province, DRC. All clients of any gender who subscribed to one of the contraceptive methods offered during these mini-campaigns were included in this study. The data were collected by 4 groups of investigators all involved in the contraceptive service offer: Community-based distributions (CBD) who are community relays trained in the offer of Community Family Planning services, the CBDa who are pupils in final classes who, in addition to the CBD package, have been trained in the administration of modern injectable methods (inplano NXT), DBCd who are pupils or students who have finished their nursing training course and by trained clinical providers with a technical platform greater than that of CBDs. The data was collected by CBD on a form previously established in the family planning service registers, CBD inputs and in the health facilities forms.

The data collected were encoded and analyzed with STATA version 14 software. The usual reduction statistics were used to describe the sample: the proportions to describe all the variables in categories and the median with its interquartile space to describe the age, the distribution not being normal. Three categories of variables were used: socio-demographic variables (age, sex, marital status, level of education, and occupation), geographic variables (urban or rural) and clinical variables (contraceptive method chosen). The age variable, initially continuous, was categorized into 3 classes, namely: Under 20, 20 to 24 and 25 and over. The variable "Method chosen", variable in category was chosen as dependent and was compared with the other socio-demographic and geographical variables. The contraceptive methods chosen were then grouped into four classes, namely: Natural non-hormonal and barrier methods comprising male and female condoms, the cycle collar, as well as Long Acting Method (LAM), oral hormonal methods comprising Combine oral contraceptive (COC), Progestative oral pill (POP) and emergency contraceptive Pill (PCU), short-term injectable hormonal methods: Sayana Press and Depo provera and long-term injectable hormonal methods (Implano NXT and Jadelle). For the logistic regression, this variable was then dichotomized into hormonal versus non-hormonal methods. Marital status has been categorized into two groups: single, divorced and widowed versus married and common-law. The 11 health zones were also grouped into two categories based on their geographic characteristics namely in urban health zones and rural health zones. The statistical analysis consisted of comparing the different proportions of the methods used in the different categories of study variables. Pearson's Chi2 test was used for the comparison of these proportions, after checking the conditions of its application. A logistic regression in multivariate analysis was done to analyze the strength of association between the use of hormonal contraceptive methods with some socio-demographic variables of female clients. For all these analyzes, a significance level of $p<5 \%$ was used.

\section{Results}

The median age (P25-P75) of clients was 25 years, and female clients accounted 
for $74.6 \%$ (Table 1 ).

Contraceptive use is also a function of the variety of methods offered to clients. Male condom remains the most popular method, followed by ECP (emergency contraceptive) and Implano NXT (Figure 1).

Depending on each variable in the study, a comparison of the different proportions of the method groups with different categories of the variables was made and revealed that the use of natural methods decreased with age and were more preferred by men $(\mathrm{p}<0.001)$ and urban customers $(\mathrm{p}=0.001)$. Women preferred long-acting, injectable hormonal methods (Table 2, Figure 2).

Table 1. Sociodemographic characteristics of clients.

\begin{tabular}{|c|c|c|}
\hline Variables & $\%$ & $\mathrm{Me}(\mathrm{EIQ})$ \\
\hline Age $($ years $)(n=1792)$ & & $25(20-30)$ \\
\hline$<20$ & 17.6 & \\
\hline $20-24$ & 30.7 & \\
\hline$\geq 25$ & 51.7 & \\
\hline \multicolumn{3}{|l|}{$\operatorname{Sex}(n=1792)$} \\
\hline Male & 24.4 & \\
\hline Female & 75.6 & \\
\hline \multicolumn{3}{|l|}{ Marital status $(\mathrm{n}=1788)$} \\
\hline Single & 46.5 & \\
\hline Common-laws Union & 2.6 & \\
\hline Married & 50.1 & \\
\hline Divorced & 0.7 & \\
\hline Widower & 0.1 & \\
\hline \multicolumn{3}{|l|}{ Level of education $(\mathrm{n}=1739)$} \\
\hline Uneducated & 8.4 & \\
\hline Primary & 16.9 & \\
\hline Secondary & 70.4 & \\
\hline Higher/University & 4.3 & \\
\hline \multicolumn{3}{|l|}{ Occupation $(\mathrm{n}=1707)$} \\
\hline No occupation & 13.8 & \\
\hline Household & 18.8 & \\
\hline Farmer & 16.9 & \\
\hline Student & 20.4 & \\
\hline Student) & 7.1 & \\
\hline Trader & 19.3 & \\
\hline State worker & 2.2 & \\
\hline Employee & 1.5 & \\
\hline \multicolumn{3}{|l|}{ Health zone $(\mathrm{n}=1793)$} \\
\hline Urban & 86.9 & \\
\hline Rural & 13.1 & \\
\hline
\end{tabular}


Table 2. Proportion of methods according to study variables.

\begin{tabular}{|c|c|c|c|c|c|}
\hline Variables & $\begin{array}{c}\text { Natural non- } \\
\text { hormonal } \\
\text { methods } \\
\%\end{array}$ & $\begin{array}{c}\text { Oral } \\
\text { hormonal } \\
\text { methods } \\
\%\end{array}$ & $\begin{array}{c}\text { Short-acting } \\
\text { injectable } \\
\text { hormonal } \\
\text { methods } \\
\%\end{array}$ & $\begin{array}{l}\text { Long-acting } \\
\text { injectable } \\
\text { hormonal } \\
\text { methods } \\
\%\end{array}$ & $\mathrm{p}$ \\
\hline Age (years) & & & & & 0.010 \\
\hline$<20$ & 48.5 & 24.6 & 7.9 & 19.0 & \\
\hline $20-24$ & 39.7 & 25.9 & 8.4 & 26.0 & \\
\hline$\geq 25$ & 34.7 & 25.8 & 10.7 & 28.8 & \\
\hline Sex & & & & & $<0.001$ \\
\hline Male & 89.1 & 10.9 & 0.0 & 0.0 & \\
\hline Female & 22.5 & 30.3 & 12.6 & 34.6 & \\
\hline Marital status & & & & & $<0.001$ \\
\hline Single, divorced and widowed & 50.8 & 25.9 & 6.8 & 16.5 & \\
\hline Married \& common-law unions & 28 & 25.3 & 12.0 & 34.7 & \\
\hline Level of education & & & & & 0.05 \\
\hline Uneducated & 39.4 & 29.6 & 7.8 & 23.2 & \\
\hline Primary & 31.7 & 25.9 & 9.7 & 32.7 & \\
\hline Secondary & 38.4 & 25.7 & 9.9 & 26.0 & \\
\hline Higher/University & 58.3 & 18.1 & 4.2 & 19.4 & \\
\hline Profession & & & & & $<0.001$ \\
\hline No occupation & 53.5 & 18.0 & 6.1 & 22.4 & \\
\hline Housewives & 22.1 & 26.4 & 14.5 & 37.0 & \\
\hline Farmers & 24.5 & 25.5 & 13.3 & 36.7 & \\
\hline Students & 48.3 & 29.4 & 4.2 & 18.1 & \\
\hline Students & 51.3 & 25.2 & 7.0 & 16.5 & \\
\hline Traders & 40.4 & 25.4 & 10.3 & 23.8 & \\
\hline state worker & 37.8 & 24.3 & 8.3 & 29.7 & \\
\hline Employees & 40.0 & 24.0 & 12.0 & 24.0 & \\
\hline Origin Health zone & & & & & $<0.001$ \\
\hline Urban area & 39.5 & 26.2 & 9.8 & 24.5 & \\
\hline Rural area & 33.9 & 21.2 & 7.9 & 37 & \\
\hline
\end{tabular}

Considering only the female, analysis included 1355 women who requested one of the methods. Implano NXT remains the most preferred method for clients, followed by PCU. The female condom and IUD are the least preferred methods (Figure 1).

Considering only female clients, the use of hormonal methods was significantly 4 times higher in women over 25 and 3 times higher in married and common-law couples (Table 3). 


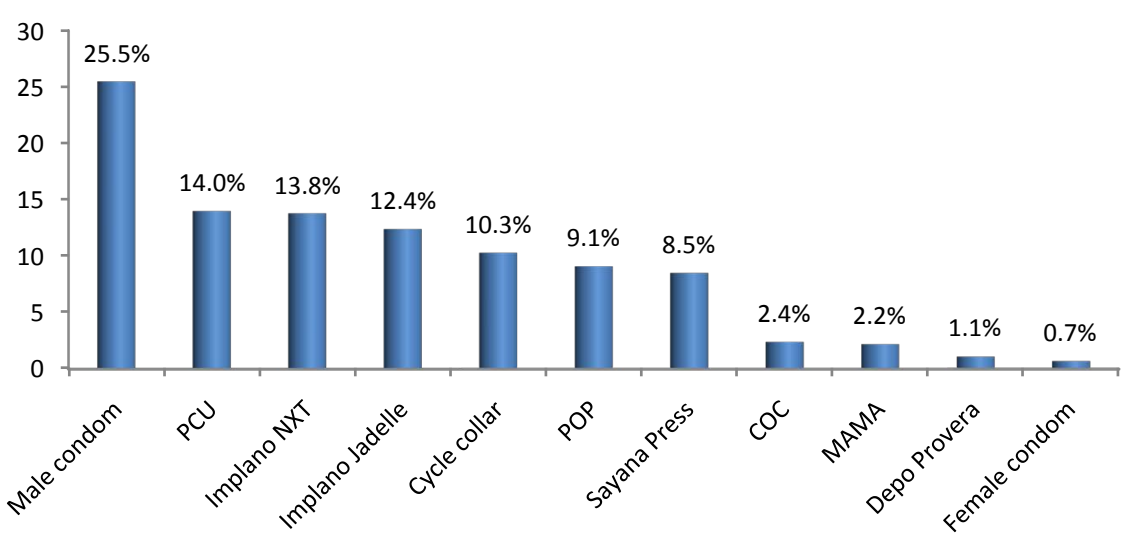

Figure 1. Profile of preferred contraceptive methods of FP clients.

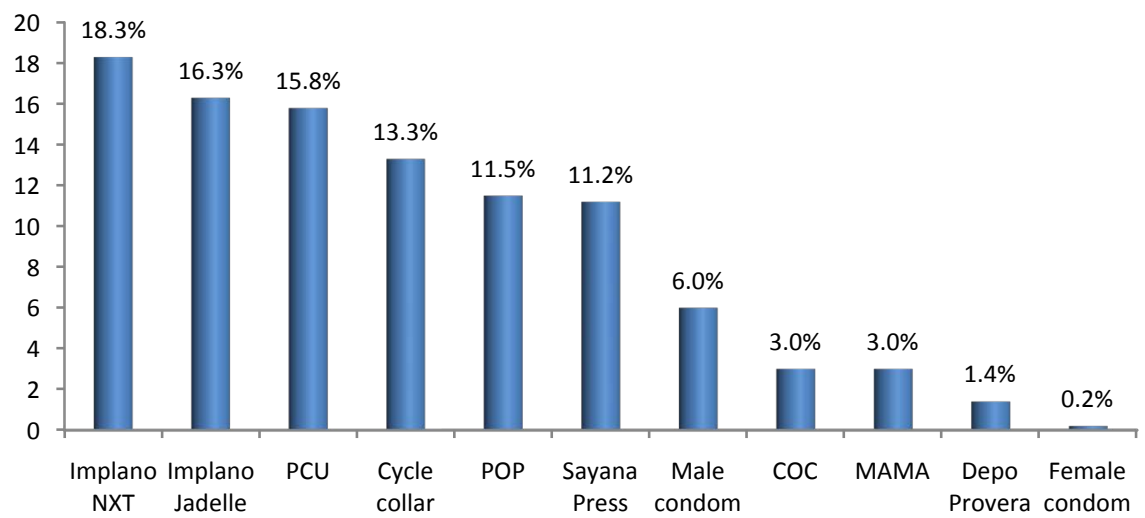

Figure 2. Proportion of methods chosen by female clients.

Table 3. Demographic characteristic of population studied.

\begin{tabular}{lccc}
\hline \multicolumn{1}{c}{ Variables } & \% HCM & Adjusted OR (IC95\%) & p-value \\
\hline $\begin{array}{l}\text { Age (years) } \\
<20\end{array}$ & 64.4 & 1 & \\
$20-24$ & 76.6 & $1.25(0.91-1.67)$ & 0.128 \\
$\geq 25$ & 82.7 & $3.56(1.43-6.52)$ & $<0.001$ \\
Marital status & & & \\
$\quad$ Single, divorced and widowed & 70.6 & 1 & $<0.001$ \\
$\quad$ Married \& common-law unions & 82.1 & $2.52(1.13-5.12)$ & \\
Level of education & & & 0.891 \\
$\quad$ Uneducated & 72.6 & 1 & 0.561 \\
$\quad$ Primary & 78.9 & $0.63(0.22-1.44)$ & 0.094 \\
$\quad$ Secondary & 73.2 & $0.96(0.41-2.26)$ & \\
$\quad$ Higher/University & 78.9 & $1.18(0.51-2.52)$ & \\
Origin Health zone & & & 0.210 \\
$\quad$ Urban area & 76.8 & $1.43(0.93-2.24)$ & \\
$\quad$ Rural area & 82.2 & &
\end{tabular}

HCM: Hormonal contraceptive methods; OR: Odd ratio. 


\section{Discussion}

The median age of clients using contraceptive methods is 25 years old. Studies carried out by other authors have also shown that the users of contraceptive methods were of young age [14] This trend can be explained in our study, by the role of a $\mathrm{CBDa}$ and $\mathrm{CBDg}$, who may have had an attractive effect of young people in favor of contraception in addition to the fact that an early onset of sexual activity is increasingly observed among young people. Male condom has been the most preferred method of customers in our series. The same trend has been observed by other authors [13] [14] [15]. In our study, we took into account clients of both sexes who may have influenced the trend in condom use. The approach used in the provision of services favoring access to both sexes, since taken separately, women have less preference for condoms; and the male condom is the best-known modern contraceptive method according to observations made by other authors [13] [14] [15]. The use of long-term contraceptive methods is proportional to age, and better accepted in rural areas than in urban areas $(\mathrm{p}<0.01)$. In our study, this is explained by the low access to the reproductive health service offer by young girls linked not only to financial and geographic access but also to gender-related barriers which are more accentuated in rural community [16] [17].

Implants (NXT and Jadelle) were the most requested methods by women in our study (34.7\%). Studies in Kinshasa and Kongo Central have shown an increase in the use of long-term methods and a decrease in the use of female condoms [6] [17]. The increase in the use of long-acting methods (Implano NXT and Jadelle) in our study is associated with the availability and diversity of the methods in the areas targeted by the study. Our results are different from those obtained in a study carried out on the determinants of the use of contraceptive methods in the Mumbunda ZS in Lubumbashi in the DRC. This showed a low use of the implant (1.6\%) while the male condom had a prevalence of $17.6 \%$ [18]. The low availability of implant would be one of the explanatory factors of this difference but also the fact that this study carried out in the health district of Lubumbashi only took into account a single health zone in which we can find people from same characteristics. However, it was carried out in 11 health zones with different characteristics (urban and rural). The attitude and behavior of the population is different depending on whether you are in a rural or an urban area. The oral hormonal method is more preferred among young clients (pupils and students) who are more motivated by the risk of early pregnancy without concern for birth spacing [15]. The level of education in our series is not associated with the use of natural non-hormonal methods, certainly living largely in a conjugal union and having a better standard of living. Oral hormonal methods were more chosen among uneducated clients and clients with secondary, primary level more opted for long-lasting injectable hormonal methods $(\mathrm{p}<0.05)$. In the sample of women taken alone, the difference between the proportions of clients who chose the methods according to the different categories of the level 
of study is not statistically significant $(\mathrm{p}=0.66)$. These results are similar to those found in the Lubumbashi study. This study showed, after adjusting for factors associated with the use of contraceptive methods, the OR according to each category of the level of education of clients and even spouses were not significant and therefore the level of education was not significant influence the choice of methods [18]. On the other hand, the DHS survey showed that the proportion of women who use a modern method increases significantly with the level of education [11]. The proportion of married and common-law unions who chose natural methods is higher than that of single, divorced and widowed persons (the use of these methods was 3 times higher among married \& common-law couples compared to single, divorced and widowed persons). This can be explained by the fact that it is in this category of brides that we find the age group over 25 who prefer long-acting methods in order to space births ( $\mathrm{p}<$ 0.001). This preference for long-lasting methods may also lead clients to seek irreversible methods, especially surgical contraception which is a contraceptive method and which must be offered and integrated among the methods in the service offering. The study carried out at the Evangelical Medical Institute of Kimpese, Democratic Republic of Congo on the impact of the use of contraception in women wishing to have tubal ligation had shown that out of a sample of 324 women analyzed, most (96\%) were over 30 and had a low level of education and $99 \%$ were married. This study concluded that the demand for surgical contraception comes mainly from married women with little education [19].

\section{Conclusion}

The unmet need for contraceptive methods still remains a problem among reproductive age population in the province of Kongo Central particularly among young people under twenty years old who have less access to contraceptive methods, compared to older group. There is a preference of women who come from rural areas, married and older for long-acting methods and those from urban areas, have a preference for natural, non-hormonal methods. This preference for long-acting contraception may also lead some women to desire irreversible contraception. Men are also interested in the offer of certain methods (male condoms, necklaces and oral hormonal methods that they request for their partners, which also require targeting men in campaigns to offer family planning services. There is therefore a need to strengthen existing efforts on contraceptive use among women of reproductive age in general and adolescents in particular. This can be achieved by empowering these young women, especially those in rural areas, to take positive reproductive health decisions to prevent unintended teenage pregnancies, HIV/AIDS and other sexually transmitted infections.

\section{Conflicts of Interest}

The authors declare no conflicts of interest regarding the publication of this paper. 


\section{References}

[1] Singh, S., Darroch, J.E., Ashford, L.S. and Vlassoff, M. (2009) Adding It Up: The Costs and Benefits of Investing in Family Planning and Maternal and Newborn Health. Guttmacher Institute et Fonds des Nations unies pour la population, New York.

[2] Liu, L., Becker, S., Tsui, A. and Ahmed, S. (2008) Three Methods of Estimating Births Averted Nationally by Contraception. Population Studies, 62, 191-210. https://doi.org/10.1080/00324720801897796

[3] Seltzer, J.R. (2002) The Origins and Evolution of Family Planning Programs in Developing Countries. RAND Corporation, Santa Monica.

[4] Dayal, M. and Barnhart, K.T. (2001) Noncontraceptive Benefits and Therapeutic Uses of the Oral Contraceptive Pill. Seminars in Reproductive Medicine, 19, 295303. https://doi.org/10.1055/s-2001-18637

[5] Maguire, K. and Westhoff, C. (2011) The State of Hormonal Contraception Today: Established and Emerging Noncontraceptive Health Benefits. American Journal of Obstetrics \& Gynecology, 205, S4-S8. https://doi.org/10.1016/j.ajog.2011.06.056

[6] DaVanzo, J., Hale, L., Razzaque, A. and Rahman, M. (2008) The Effects of Pregnancy Spacing on Infant and Child Mortality in Matlab, Bangladesh: How They Vary by the Type of Pregnancy Outcome That Began the Interval. Population Studies, 62, 131-154. https://doi.org/10.1080/00324720802022089

[7] Yeakey, M.P., Muntifering, C.J., Ramachandran, D.V., Myint, Y., Creanga, A.A. and Tsui, A.O. (2009) How Contraceptive Use Affects Birth Intervals: Results of a Literature Review. Studies in Family Planning, 40, 205-214. https://doi.org/10.1111/j.1728-4465.2009.00203.x

[8] World Health Organisation (2016) Report of Monitoring Health for the Sustaintable Development Goals. World Health Organisation, Geneva.

[9] Victora, C.G., Requejo, J.H., Barros, A.J., Berman, P., Bhutta, Z., Boerma, T., Chopra, M., de Francisco, A., Daelmans, B., Hazel, E., Lawn, J., Maliqi, B., Newby, H. and Bryce, J. (2016) Countdown to 2015: A Decade of Tracking Progress for Maternal, Newborn, and Child Survival. The Lancet, 387, 2049-2059.

https://doi.org/10.1016/S0140-6736(15)00519-X

[10] Democratic Republic of the Congo (2014) Ministère du Plan. Enquête Démographique et de Santé Rapport Préliminaire. Democratic Republic of the Congo, Kinshasa.

[11] Ntambue, A.M., Tshiala, R.N., Malonga, F.K., Ilunga, T.M., Kamonayi, J.M., Kazadi, S.T., Matungulu, C.M., Musau, A.N., Mulamba, D., Dramaix-Wilmet, M. and Donnen, P. (2017) Utilisation des méthodes Contraceptives Modernes en République Démocratique du Congo: prévalence et barrières dans la zone de santé de Dibindi à Mbuji-Mayi. Pan African Medical Journal, 26, 199. https://doi.org/10.11604/pamj.2017.26.199.10897

[12] Fryatt, R., Mills, A., Nordstrom, A. and Asia, S. (2010) Financing of Health Systems to Achieve the Health Millennium Development Goals in Low-Income Countries. Lancet, 375, 419-426. https://doi.org/10.1016/S0140-6736(09)61833-X

[13] Ministère de la santé publique (2014) Planification Familiale: Plan Stratégique National À Vision Multisectorielle (2014-2020). Democratic Republic of the Congo, Kinshasa.

[14] Ntambue, A.M., Tshiala, R.N., Malonga, F.K., Ilunga, T.M., Kamonayi, J.M., Kazadi, S.T., et al. (2017) Utilisation des méthodes contraceptives modernes en République 
Démocratique du Congo: prévalence et barrière dans la Zone de Santé de Dibindi à Mbuji-Mayi. Pan African Medical Journal, 26, Article No. 199.

https://doi.org/10.11604/pamj.2017.26.199.10897

[15] Marie-Jeanne, K.F. (2017) Déterminants de la faible utilisation des méthodes contraceptives modernes chez les femmes en âge de procréer cas de la Zone De Sante de Gombe Matadi. Mémoire présenté et défendu en vue de l'obtention du diplôme de Spécialiste en Santé Publique. Année Académique 2016-2017.

[16] Ecole de Santé Publique de Kinshasa (2020) PMA République Démocratique du Congo (Kinshasa). Utilisation de la Contraception.

[17] Ecole de Santé Publique de Kinshasa (2020) PMA République Démocratique du Congo (Kongo Central). Utilisation de la Contraception 2020.

[18] Matungulu, C.M., Kandolo, S.I., Mukengeshayi, A.N., Nkola, A.M., Mpoyi, D.I., Mumba, S.K., Kabamba, J.N., Cowgill, K. and Kaj, F.M. (2015) Déterminants de l'utilisation des méthodes contraceptives dans la Zone de Santé Mumbunda à Lubumbashi, République Démocratique du Congo. Pan African Medical Journal, 22, Article No. 329. https://doi.org/10.11604/pamj.2015.22.329.6262

[19] Chabikuli, N. and Lukanu, P.N. (2007) Impact of Contraception Use among Women Seeking Tubal Ligation in the Rural Democratic Republic of the Congo. South African Journal of Obstetrics and Gynaecology, 13, 15-18. 